\section{Coming to terms with animals}

Ralph A. Lewin

The Concise Dictionary of Zoology. By Michael Allaby. Oxford University Press: 1991. Pp. 508. £20, \$39.95.

IF you are working at the cutting edge of zoology - which I conceive to be more like a fractal fringe - you may not find your pet animal listed here. After all, you may be studying it precisely because so little is known about it. For instance, my own work years ago concerned the bursa Fabricii* of woodpigeons*: later it took me to coral-reef areas, some depredated by crown-of-thorns* starfish, others patchily carpeted with didemnids* (phycozoans* containing algae long regarded as zoochlorellae*) I found there a tectibranch* mollusc with green symbiotic chloroplasts from its ingested algae. My wife works with sea-skaters* (Halobates*), perhaps the most widespread of all insects, and other components of the marine pleuston*. (Neuston is not the same as pleuston: neustonic organisms live under the surface, pleustonic ones on top of it.) None of the asterisked words appears in this dictionary.

It is a general dictionary practice to alphabetize nouns and not their qualifiers when listing such items as Andean condor, bee humming-bird, edible frog, imperial pigeon, lungless salamander, noisy scrub-bird, rock rat, rough-toothed dolphin, screech owl and spider-hunting wasp. Allaby does otherwise, which I consider a point in the dictionary's disfavour. But blue butterflies, with a special family identity, could reasonably be listed in this way, and no rational zoologist would look up blue-bottles as bottles, blue.

My wife and I spent a couple of hours thinking of words that could have been included but were not, and easily came up with some 60 . Acantharia, alewife, appendicularia, bloodworm, bobcat, brolga, budworm, cahaug, caprellid ..... We then checked to see which of these could be found in the two comparable dictionaries of zoology in our library: that by A. W. Leftwich published by Constable in $1973(7,600$ words) and that by S. W. Pennak published by Ronald in 1964 (19,000 words). About one-quarter of our items were found in Leftwich, and about two-thirds in Pennak. (We did not make such comparisons the other way round.) Our friendly librarian, who also compared these three dictionaries, expressed an enthusiastic preference for Allaby, which of course is much more up to date than the others. (Another colleague to whom I showed this dictionary dismissed it because it does not include the vocabulary of molecular biology. I think this criticism is unreasonable: for such terms one should look elsewhere. Likewise, one should not expect to find here more than a small fraction of the 100,000 terms listed in one of the bigger medical dictionaries.) It was also pointed out to me that popular names of fishes in particular are far from standard. A monkfish may be an angler-fish in one diocese, a shark in another. Definitions of eels - common or garden or whatever - are even more slippery. The Fish List, a Food and Drug Administration guide published in 1988 by the US Government Printing Office, Washington DC, has many other examples of this sort.

With about 300,000 (give or take an order of magnitude) genera of animals, living and fossil, ranging in size from dinoflagellates to dinosaurs, one could not expect more than a small fraction to be listed here. This is primarily an English-language dictionary, with about 6,000 entries, and as such it should not be overladen with Graeco-Latin names. Only a few-hundred generic names are included. I would have preferred to find a few more with special biochemical, economic, genetic, political or sociological importance, such as Acanthaster, Achatina, Artemia, Betta, Caenorhabditis, Lumbricus and Tribolium. (For fun, I would also like to have seen included a few items such as griffin, mermaid, rhinograde, roc, unicorn and yeti; but maybe this is too serious a compilation

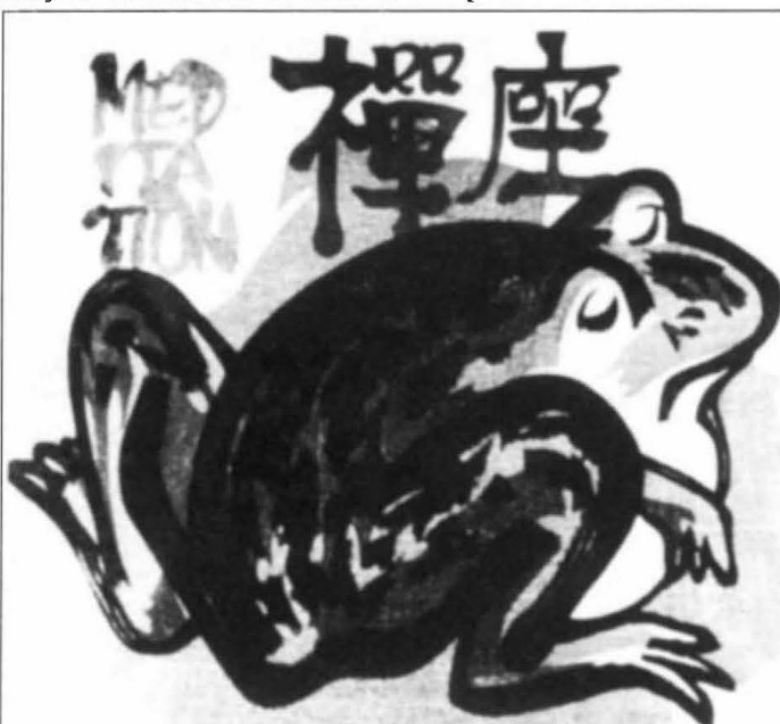
Moon itself, causing an eclipse. These and other such fascinating details can be found in Robert DeGraff's Book of the Toad, a colourful and witty pot-pourri on the toad's place in science, history and mythology. Published by Park Street/Lutterworth, price is $\$ 19.95, £ 12.95$. is represented as a creature of supernatural power, but also viewed with affection and described with wit. The Asian Bufo is usually found presiding over magic, being a master of escape who takes pills that transform humans into toads (or vice versa) and who knows the secret of eternal life. Bufo is lumped together with the loathsome creatures that represent the "evil, dark feminine forces" of yin, the ultimate manifestation of which is the Moon; so it is hardly surprising that the Chinese see not a man but a toad in the Moon. In a story that dates to the Han dynasty (200 BC), the Moon-toad, apparently not satisfied with for such frivolities.) There are many names of families (usually, although not consistently, with numbers of genera), orders (usually with numbers of families), classes and higher taxa. Also listed are popular as well as classical (unpopular?) names, ecological concepts, physiological phenomena and so on. Certainly some special names for funny bits of scales and spines, ossicles and follicles, peculiar lobes of mandibles and recondite bits of genitalia unmentionable here have been omitted, perhaps rightly. But on the whole, this is a fine compendium of unquestionable use. I have already found myself referring to it as I confer with my zoological colleagues or watch nature programmes on television.

What would I recommend for the next edition? (There surely will be one.) I would suggest excluding terms not immediately relevant to a zoological dictionary, such as acid, biosynthesis, chisquared, information statistic, innate, kinase, over-specialization, quinone secondary structure, Schiff's reagent and wobble hypothesis. And I would reduce the length of many of the entries, as this is not an encyclopaedia or a textbook. Do we need more than 100 words for entries such as Asilidae, thelytoky and thylacine? I think not: saving some of the space and including more different entries might make the book even more valuable next time round.

Rightly, I think, derivations of terms have not been given. Cross-indexing and proof-reading seem to have been done impeccably, as one would expect for a work from this publishing stable. Make sure you have an Allaby handy: you will undoubtedly find it useful.

Ralph A. Lewin is at the Scripps Institution of Oceanography, University of California, La Jolla, California 92093-0202, USA. 